\title{
Silver Nanoparticle Oligonucleotide Conjugates Based on DNA with Triple Cyclic Disulfide Moieties
}

\author{
Jae-Seung Lee, Abigail K. R. Lytton-Jean, Sarah J. Hurst, and Chad A. Mirkin* \\ Department of Chemistry and International Institute for Nanotechnology, Northwestern University, \\ 2145 Sheridan Road, Evanston, IL 60208
}

\section{Abstract}

We report a new strategy for preparing silver nanoparticle oligonucleotide conjugates that are based upon DNA with cyclic disulfide-anchoring groups. These particles are extremely stable and can withstand $\mathrm{NaCl}$ concentrations up to $1.0 \mathrm{M}$. When silver nanoparticles functionalized with complementary sequences are combined, they assemble to form DNA-linked nanoparticle networks. This assembly process is reversible with heating and is associated with a red-shifting of the particle surface plasmon resonance and a concomitant color change from yellow to pale red. Analogous to the oligonucleotide-functionalized gold nanoparticles, these particles also exhibit highly cooperative binding properties with extremely sharp melting transitions. This work is an important step towards being able to use silver nanoparticle oligonucleotide conjugates for a variety of purposes, including molecular diagnostic labels, synthons in programmable materials synthesis approaches, and functional components for nanoelectronic and plasmonic devices.

The discovery and development of DNA-functionalized gold nanoparticle conjugates (DNAAu NPs) in $1996^{1,2}$ has opened up opportunities for fundamental studies of their novel properties $^{3-6}$ as well as their application in the assembly of advanced superstructures, ${ }^{1,2,7}$ the detection of nucleic acids, proteins, metal ions, and small molecules, ${ }^{8-22}$ and as gene silencing agents. ${ }^{23}$ The utility of DNA-Au NPs is, in part, due to their intense optical, catalytic, and synthetically programmable recognition properties. In addition, when chemically modified in the appropriate manner, they can exhibit highly cooperative binding properties, which are typically characterized by extremely sharp melting transitions. ${ }^{4}$ The identification of this cooperativity has led to the development of molecular diagnostic probes that exhibit much higher selectivity and sensitivity for target analytes than conventional molecular fluorophore probes, ${ }^{8,19,24-26}$ and "antisense particle" agents that are significantly more effective at gene knockdown than free DNA based antisense agents. ${ }^{23}$

Silver nanoparticles (Ag NPs) also have generated significant scientific and technological interest. ${ }^{27-29}$ These particles exhibit higher extinction coefficients relative to gold nanoparticles of the same size, possess a particle size-dependent surface plasmon resonance between $\sim 390$ and $420 \mathrm{~nm}$, are electrochemically and catalytically active, and exhibit Raman enhancement properties. ${ }^{28-31}$ As has been extensively demonstrated with gold, ${ }^{1,4,32,33}$ a common method used to functionalize the surface of noble metals is the adsorption of thiolcontaining molecules. However, there have been only a few reports of thiol-functionalized $\mathrm{Ag} \mathrm{NPs},{ }^{34,} 35$ and of the structures prepared, all: (1) show limited stability in saline buffer (up to $0.3 \mathrm{M}$ salt concentration), (2) typically require lengthy synthetic procedures (more than 2 days), and (3) do not exhibit highly cooperative binding as determined by melting

chadnano@northwestern.edu.

Supporting Information Available. Materials, Experimental details for the oligonucleotide synthesis, TEM Analysis, Repeated melting experiments of DNA-Ag NP aggregates. This material is available free of charge via the Internet at http://pubs.acs.org. 
analyses (the melting transitions for the hybridized particle aggregates span $\geq 10^{\circ} \mathrm{C}$ ). Moreover, the possible oligonucleotides that can be used to stabilize the particles are limited with respect to sequence (e.g. poly adenine (A) sequences). ${ }^{34,35}$ These limitations are primarily due to the chemical degradation of the Ag NPs under the functionalization conditions and the susceptibility of the silver surface to oxidation. ${ }^{27,36}$

As a result of these limitations, alternative approaches have been developed to enable the conjugation of DNA to Ag NPs. Attempts to modify the Ag NP surface with more tailorable and robust materials such as gold, silica, or polymers have been considered. ${ }^{27,37-39}$ However, they require additional cumbersome chemical modification steps. Herein, we present a method to functionalize Ag NPs with oligonucleotides modified with terminal cyclic disulfide groups. These DNA-functionalized silver particles (DNA-Ag NPs) can be synthesized in less than $30 \mathrm{~min}$ and show stability at high salt concentrations $(1.0 \mathrm{M} \mathrm{NaCl})$. Significantly, the DNA-Ag NPs also exhibit high cooperativity as characterized by their sharp DNA melting transitions (full width at half-maximum $(\mathrm{FWHM})=\sim 2{ }^{\circ} \mathrm{C}$ ).

In a typical experiment, $1 \mathrm{OD}$ of an oligonucleotide modified with three cyclic disulfide units (1: 5'(DSP) $)_{3}-\mathrm{A}_{10}$-ATT-ATC-ACT 3'; 2: 5' (DSP) ${ }_{3}$-A A $_{10}$-AGT-GAT-AAT 3'; DSP: cyclic disulfide-containing phosphate derivative; see Figure 1A and Supporting Information) was added to $1 \mathrm{~mL}$ of $\mathrm{Ag} \mathrm{NP}(20 \mathrm{~nm}$ in diameter, $1.2 \mathrm{nM})$ solution. The final oligonucleotide concentration is $\sim 4.7 \mu \mathrm{M}$, and the final Ag NP concentration is $\sim 1 \mathrm{nM}$ $\left(\varepsilon_{410 \mathrm{~nm}}=7.1 \times 108 \mathrm{~cm}^{-1} \mathrm{M}^{-1}\right) .{ }^{40}$ This step was followed by the addition of $1 \%$ sodium dodecyl sulfate (SDS) aqueous solution (final concentration $=0.01 \%$ SDS) and $100 \mathrm{mM}$ phosphate buffer (final concentration $=10 \mathrm{mM}$ phosphate, $\mathrm{pH}$ 7.4). Over a period of $30 \mathrm{~min}$, $2 \mathrm{M} \mathrm{NaCl}$ solution was added in a stepwise manner (final concentration $=0.15 \mathrm{M} \mathrm{NaCl}$ ). The solution was incubated overnight at room temperature, followed by centrifugation to isolate the particles. The supernatant was removed, and the particles were redispersed in phosphate buffer $(0.01 \%$ Tween $20,10 \mathrm{mM}$ phosphate, a desired concentration of $\mathrm{NaCl}, \mathrm{pH}$ 7.4). This step was repeated three times to eliminate residual DNA. Equal concentrations of Ag NPs modified with sequence $\mathbf{1}$ or sequence $\mathbf{2}$ were combined and allowed to hybridize at room temperature (Figure 1A).

To successfully immobilize oligonucleotides on the Ag NP surface, we first considered the interaction between the silver surface and the surface binding groups of the oligonucleotides, which is affected by the number of binding groups. Recently, our group reported that multiple thiol groups increase the binding affinity of oligonucleotides for the Au NP surface, which results in nanoparticle probes with higher stabilities. ${ }^{41}$ This strategy is based upon the fact that polydentate ligands often form more substantially stable metal-ligand complexes than monodentate ligands. ${ }^{42}$ Therefore, utilization of multiple anchoring groups on the oligonucleotides should lead to higher stability Ag NP oligonucleotide conjugates. In addition, our group also demonstrated that oligonucleotides containing a cyclic disulfide anchoring group bind readily to Au NPs with higher affinity than monothiol or acyclic disulfide groups. ${ }^{43}$ Therefore, we designed an oligonucleotide sequence containing three cyclic disulfide moieties as anchoring groups (Figure 1A).

In order to study the properties of DNA-Ag NPs, two batches of silver nanoparticles were functionalized with complementary oligonucleotide sequences (sequence $\mathbf{1}$ and $\mathbf{2}$, respectively), Figure 1A. Unmodified silver nanoparticles exhibit a surface plasmon resonance at $410 \mathrm{~nm}$ (Figure 1B), and therefore they exhibit an intense yellow color (Figure 1C-1). Interestingly, when Ag NPs are modified with either sequence $\mathbf{1}$ or $\mathbf{2}$, respectively, they do not show any noticeable changes in their UV-vis spectrum, indicating that the particles are stable and do not aggregate. This has been confirmed by TEM analysis of the modified particles (see Supporting Information). However, when DNA-Ag NPs, modified 
with complementary sequences $\mathbf{1}$ and $\mathbf{2}$, respectively, are combined, the plasmon resonance dampens and red-shifts from 410 to $560 \mathrm{~nm}$ (Figure 1B). This dampening and red-shifting is a result of particle assembly due to hybridization, which can be observed with the naked eye in the form of a color change from bright yellow to pale red. (Figure 1C). Since the process is due to DNA hybridization, it is reversible, and upon heating, the color of the solution returns to an intense yellow, a diagnostic indicator of dehybridization in this system. (Figure 1C-1).

The reversible nature of the DNA-Ag NP hybridization process was further characterized by monitoring the melting process at $410 \mathrm{~nm}$ as a function of temperature (Figure 2). Importantly, the DNA-linked Ag NPs exhibit a sharp melting transition similar to that characteristic of the analogous DNA-linked Au NP aggregates, ${ }^{4}$ indicating that DNA-linked Ag NPs also exhibit highly cooperative binding properties. The melting temperature $\left(T_{\mathrm{m}}\right)$ of the DNA-linked Ag NPs, $46.5^{\circ} \mathrm{C}$, was obtained by taking the maximum of the first derivative of the melting profile. The FWHM of the first derivative (Figure 2, inset) is $\sim 2.4$ ${ }^{\circ} \mathrm{C}$, which is comparable to the typical sharp melting transition of DNA-linked Au NPs $\left(\mathrm{FWHM}=\sim 2.2^{\circ} \mathrm{C}\right) .{ }^{24}$ Significantly, this melting transition was found to be highly reproducible, as demonstrated by repeated hybridization/melting experiments, which were performed with the same sample of the DNA-Ag NPs over a period of one week (see Supporting Information). This reproducibility is strong evidence that the modification of the Ag NP surface with oligonucleotides through a triple cyclic disulfide anchor is strong enough to stabilize the DNA-Ag NP probes against heat, aging, and degradation in aqueous media.

To determine the effect of the salt concentration on the melting properties of DNA-Ag NP aggregates, we monitored the melting transitions of DNA-Ag NP aggregates as a function of $\mathrm{NaCl}$ concentration. As expected, the melting transitions occur at higher temperatures as the salt concentration increases due to enhanced screening, which decreases the repulsion between the negatively charged oligonucleotides, as previously reported with DNA-Au NPs (Figure $3 \mathrm{~A}) .{ }^{4}$ The $T_{\mathrm{m}}$ spans the range from $46.5^{\circ} \mathrm{C}$ to $58.8^{\circ} \mathrm{C}$, as the salt concentration is increased from $0.15 \mathrm{M}$ to $0.70 \mathrm{M}$ (Figure $3 \mathrm{~B}$ ). Note that the functionalized Ag NPs are stable at high salt concentrations (up to $1.0 \mathrm{M} \mathrm{NaCl}$ ). Importantly, all of the melting transitions are extremely sharp over the entire salt concentration range studied (FWHM $\leq \sim$ $2.5^{\circ} \mathrm{C}$ ). This observation demonstrates that one can control the DNA-Ag NP hybridization and dehybridization process by adjusting salt concentrations similar to the control afforded by DNA-Au NPs.

In conclusion, we have developed a method for synthesizing stable DNA-functionalized silver nanoparticles that exhibit distant-dependent optical properties and highly cooperative binding properties, as demonstrated by sharp melting transitions. This method takes advantage of the strong affinity of multiple cyclic disulfide anchoring moieties for the silver nanoparticle surface. This work is important as it: (1) allows one to use Ag NPs in programmable material syntheses and as biodiagnostic probes with highly advanced functionalities, (2) demonstrates the use of cyclic disulfide moieties as anchoring groups on a silver nanoparticle surface, and (3) in principle, should be applicable to the functionalization of anisotropic silver nanomaterials with DNA. ${ }^{44-47}$

\section{Supplementary Material}

Refer to Web version on PubMed Central for supplementary material. 


\section{Acknowledgments}

CAM acknowledges AFOSR, NSEC/NSF, CCNE and NIH for support of this research. CAM is also grateful for a NIH Director's Pioneer Award.

\section{References}

1. Mirkin CA, Letsinger RL, Mucic RC, Storhoff JJ. Nature. 1996; 382:607-609. [PubMed: 8757129]

2. Alivisatos AP, Johnsson KP, Peng X, Wilson TE, Loweth CJ, Bruchez MP, Schultz PG. Nature. 1996; 382:609-611. [PubMed: 8757130]

3. Storhoff JJ, Lazarides AA, Mucic RC, Mirkin CA, Letsinger RL, Scatz GC. J Am Chem Soc. 2000; 122:4640-4650.

4. Jin R, Wu G, Li Z, Mirkin CA, Schatz GC. J Am Chem Soc. 2003; 125:1643-1654. [PubMed: 12568626]

5. Lytton-Jean AKR, Mirkin CA. J Am Chem Soc. 2005; 127:12754-12755. [PubMed: 16159241]

6. Lee J-S, Stoeva SI, Mirkin CA. J Am Chem Soc. 2006; (128):8899-8903. [PubMed: 16819885]

7. Niemeyer CM, Simon U. Eur J Inorg Chem. 2005:3641-3655.

8. Rosi NL, Mirkin CA. Chem Rev. 2005; 105:1547-1562. [PubMed: 15826019]

9. Nam JM, Thaxton CS, Mirkin CA. Science. 2003; 301:1884-1886. [PubMed: 14512622]

10. Stoeva SI, Lee JS, Thaxton CS, Mirkin CA. Angew Chem Int Ed. 2006; 118:3381-3384.

11. Liu J, Lu Y. Angew Chem Int Ed. 2006; 45:90-94.

12. Lee J-S, Han MS, Mirkin CA. Angew Chem Int Ed. 2007 Early View.

13. Cerruti MG, Sauthier M, Leonard D, Liu D, Duscher G, Feldheim DL, Franzen S. Anal Chem. 2006; 78:3282-3288. [PubMed: 16689528]

14. He L, Musick MD, Nicewarner SR, Salinas FG, Benkovic SJ, Natan MJ, Keating CD. J Am Chem Soc. 2000; 122:9071-9077.

15. Pavlov V, Xiao Y, Shlyahovsky B, Willner I. J Am Chem Soc. 2004; 126:11768-11769. [PubMed: 15382892]

16. Niemeyer CM. Angew Chem Int Ed. 2001; 40:4128-4158.

17. Huang CC, Huang YF, Cao Z, Tan W, Chang HT. Anal Chem. 2005; 77:5735-5741. [PubMed: 16131089]

18. Su M, Li S, Dravid VP. Appl Phys Lett. 2003; 82:3562-3564.

19. Han MS, Lytton-Jean AKR, Oh BK, Heo J, Mirkin CA. Angew Chem Int Ed. 2006; 45:18071810.

20. Maxwell DJ, Taylor JR, Nie S. J Am Chem Soc. 2002; 124:9606. [PubMed: 12167056]

21. Sato K, Hosokawa K, Maeda M. J Am Chem Soc. 2003; 125:8102-8103. [PubMed: 12837070]

22. Li H, Rothberg LJ. J Am Chem Soc. 2004; 126:10958-10961. [PubMed: 15339181]

23. Rosi NL, Giljohann DA, Thanxton CS, Lytton-Jean AKR, Han MS, Mirkin CA. Science. 2006; 312:1027-1030. [PubMed: 16709779]

24. Storhoff JJ, Elghanian R, Mucic RC, Mirkin CA, Letsinger RL. J Am Chem Soc. 1998; 120:1959_ 1964.

25. Han MS, Lytton-Jean AKR, Mirkin CA. J Am Chem Soc. 2006; 128:4954-4955. [PubMed: 16608320]

26. Nam JM, Stoeva SI, Mirkin CA. J Am Chem Soc. 2004; 126:5932-5933. [PubMed: 15137735]

27. Cao Y, Jin R, Mirkin CA. J Am Chem Soc. 2001; 123:7961-7962. [PubMed: 11493092]

28. Braun G, Lee SJ, Dante M, Nguyen T-Q, Moskovits M, Reich N. J Am Chem Soc. 2007 ASAP.

29. Mulvaney P. Langmuir. 1996; 12:788-800.

30. Link S, Wang ZL, El-Sayed MA. J Phys Chem B. 1999; 103:3529-3533.

31. Jiang ZJ, Liu CY, Sun LW. J Phys Chem B. 2005; 109:1730-1735. [PubMed: 16851151]

32. Hurst SJ, Lytton-Jean AKR, Mirkin CA. Anal Chem. 2006; 78:8313-8318. [PubMed: 17165821]

33. Demers LM, Mirkin CA, Mucic RC, Reynolds RA, Letsinger RL, Elghanian R, Viswanadham G. Anal Chem. 2000; 72:5535-5541. [PubMed: 11101228] 
34. Tokareva I, Hutter E. J Am Chem Soc. 2004; 126:15784-15789. [PubMed: 15571402]

35. Vidal BC, Deivaraj TC, Yang J, Too HP, Chow GM, Gan LM, Lee JY. New J Chem. 2005; 28:812-816.

36. Yin Y, Li ZY, Zhong Z, Gates B, Xia Y, Venkateswaran S. J Mater Chem. 2002; 12:522-527.

37. Liu S, Zhang Z, Han M. Anal Chem. 2005; 77:2595-2600. [PubMed: 15828798]

38. Quaroni L, Chumanov G. J Am Chem Soc. 1999; 121:10642-10643.

39. Chen Y, Aveyard J, Wilson R. Chem Commun. 2004:2804-2805.

40. The molar extinction coefficient is calculated from the measured UV-Vis extinction of a colloid and a particle concentration known from the manufacturer.

41. Li Z, Jin R, Mirkin CA, Letsinger RL. Nucleic Acids Res. 2002; 30:1558-1562. [PubMed: 11917016]

42. Cotton, FA.; Wilkinson, G.; Murillo, CA.; Bochmann, M. Advanced Inorganic Chemistry. 6. John Wiley \& Sons; New York: 1999. p. 27-29.

43. Letsinger RL, Elghanian R, Viswanadha G, Mirkin CA. Bioconjugate Chem. 2000; 11:289-291.

44. Jin R, Cao Y, Mirkin CA, Kelly KL, Schatz GC, Zheng JG. Science. 2001; 294:1901-1903. [PubMed: 11729310]

45. Hao E, Kelly KL, Hupp JT, Schatz GC. J Am Chem Soc. 2002; 124:15182-15183. [PubMed: 12487587]

46. Wiley B, Herricks T, Sun Y, Xia Y. Nano Lett. 2004; 4:1733-1739.

47. Jana NR, Gearheart L, Murphy CJ. Chem Commun. 2001:617-618. 


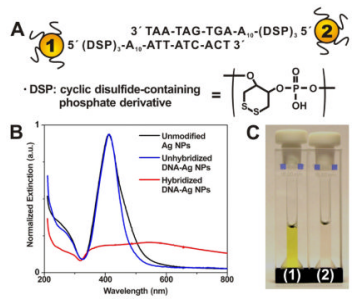

Figure 1.

(A) Schematic illustration of the hybridization of two complementary DNA-Ag NPs. (B) UV-vis spectra of unmodified Ag NPs (black line), unhybridized DNA-Ag NPs (blue line), and hybridized DNA-Ag NPs (red line). Note that the wavelength at which the maximum of the extinction of Ag NPs is obtained remains the same after DNA-functionalization. After hybridization, however, the band of DNA-Ag NPs broadens and red-shifts significantly from $410 \mathrm{~nm}$ to $560 \mathrm{~nm}$. (C) Colorimetric change responsible for the assembly process of DNAAg NPs. The intense yellow color of the unhybridized Ag NPs (C1) turns to pale red (C2) as the particle aggregation proceeds. Heating of (C2), however, results in the return of the solution color to yellow (C1). 


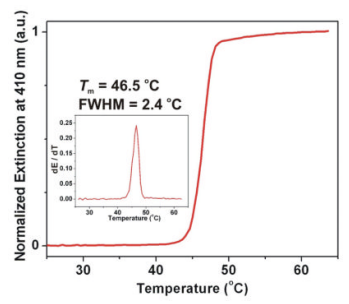

Figure 2.

The melting transition for the DNA-Ag NP aggregates as monitored by the extinction of the Ag nanoparticles at $410 \mathrm{~nm}$ as a function of temperature $\left(T_{\mathrm{m}}=46.5^{\circ} \mathrm{C}\right)$. The concentration of nanoparticles is $1 \mathrm{nM}$ (total). Note that the melting temperature is $46.5^{\circ} \mathrm{C}$ and the melting transition is extremely sharp $\left(\mathrm{FWHM}=2.4^{\circ} \mathrm{C}\right)$, which is comparable to that of DNA-Au NP aggregates. 

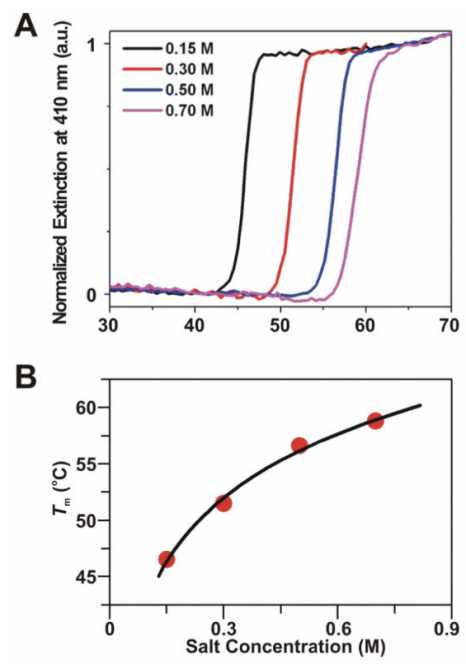

Figure 3.

(A) Melting transitions for DNA-Ag NP aggregates (20 nm in diameter) at various salt concentrations: $0.15 \mathrm{M}, 0.30 \mathrm{M}, 0.50 \mathrm{M}$ and $0.70 \mathrm{M}$. The concentration of Ag NPs is $1 \mathrm{nM}$ (total). (B) A plot of $T_{\mathrm{m}}$ as a function of salt concentration. 